\title{
Problems and Countermeasures of Modern Construction Engineering Technology Management
}

\author{
Lijian Pei \\ Institute of Architectural Engineering, Kunming Metallurgy College, Kunming, China
}

Keywords: modern architecture; architectural engineering; engineering technology; engineering management

\begin{abstract}
Modern construction engineering technology management work is a basic management work of construction enterprises, and its management effectiveness will directly affect the development prospects of construction enterprises. By optimizing the technical management means of construction engineering, the efficiency of building construction can be effectively improved, thereby improving the quality of construction engineering. Based on the content of construction project technical management work, this paper first analyzes the importance of construction management technology management methods. Secondly, it discusses the problems existing in modern construction engineering technology management. Finally, it puts forward the optimization of modern construction technology management.
\end{abstract}

\section{Introduction}

Modern construction engineering technology management work includes many aspects, such as technical management work, management system formulation work, file management work, technical training management work, drawing review work, preparation and application work, and "four new" technology development and application management work and many more [1]. With the current increase in construction projects and the rapid development of urban construction, construction competition has become increasingly fierce, and the competitive forces reflected by the level of technical management are also particularly prominent. Some enterprises have superficial capital and rich technical reserves on the surface, but because there is no Good technical management, or a sound management system, therefore, often in a passive, unfavorable position in the competition process, which fully illustrates the important position of technology management in the enterprise.

\section{Construction Engineering Technology Management and Significance}

In the management of construction projects, construction engineering technology management is a very important part of it, which is very important for the future development of the company. Combined with the current actual situation, it can be seen that the management of construction engineering technology has certain diversity. Only by continuously optimizing each management detail can the construction safety and quality be maximized [1]. By selecting advanced engineering and technical means of operation, the construction efficiency of the project can be improved, and at the same time, the construction can be carried out in strict accordance with the corresponding specifications [1]. In addition, by strengthening the management of engineering technology, it is possible to further enhance the competitiveness of construction units and expand competitive advantages, so that the business benefits of construction units will continue to increase.

\subsection{Construction engineering management.}

The technical management of construction enterprises is to be the general term for various construction techniques, various technical activities, various elements of the construction process, the use of scientific methods, control and regulation, organization and play, planning and decision-making [2]. Construction engineering is a comprehensive project involving complex projects, multi-operations, and a variety of technologies. The technical activities of construction 
companies are also very extensive, including familiarity with design drawings, review of drawings, and preparation of construction organization design [2]. During the construction process, various technical tasks such as negotiation management, inspection quality, and completion acceptance are discussed. In the process of building construction technology management, its control points are reflected in the following aspects:

\subsection{The significance of construction engineering technology management.}

During the construction process, construction technology management has played a very important role and role, and must be highly valued by the personnel involved in the construction project. The important task of construction technology management is to apply the specific functions and scientific methods of management to promote the continuous development of technical work [2]. In the construction process, strictly follow the required technical policies, regulations and indicators of the technical management department. Reasonable arrangement of various technical work, construction of good technical procedures to ensure that the overall production process meets the normative requirements, in order to achieve the dialectical unity of production technology, quality progress and economic technology [1]. Effectively reduce costs, improve economic efficiency, better contact with actual engineering conditions, conduct technical research, continuously summarize experience, and innovate construction methods.

\section{Problems in Modern Construction Engineering Technology Management}

In the modern construction engineering technology management work, there are still many problems. For example, there is no sound construction engineering technology management organization system; the construction engineering management system is flawed; the construction engineering technology supervision and management is lacking.

\subsection{The lack of sound construction engineering technology management organization system.}

The construction industry is relatively large, and there are differences in the scale and software and hardware facilities of a construction enterprise. In addition, the construction system is a system of total subcontracting, which makes it difficult to establish a standardized and comprehensive management system within the industry [3]. However, for such a complex industry, the lack of an effective, scientific and rational management system, it is difficult to achieve greater results in the technical management of the project construction project.

\subsection{Defects in the construction engineering technology management system.}

Due to the uneven situation of construction enterprises, some enterprises cannot implement the national standardization standards for project construction [3]. For example, these local standards and industry standards, for small-scale enterprises with poor construction techniques, have limited ability to implement these standards, so the implementation effect will be greatly reduced. In addition, some construction companies have not established a sound management system, and relevant responsibilities have not been well implemented, which directly affects the supervision, which is not conducive to improving the effectiveness of enterprise project construction engineering technology management.

\subsection{Non-standardized drawing review.}

In the design of modern architectural drawings, the design work of the drawings is provided by the construction company to the design company, and then the design company designs the drawings according to the materials and requirements provided by the construction enterprise [4]. In this process, the design company needs to carry out the construction area. However, in the actual design process, the architectural design company often causes errors and omissions in the drawing design due to various factors. 


\subsection{Cumbersome and complicated construction techniques.}

Modern buildings use far more functions than traditional buildings, and in order to meet the various needs of the building, it is necessary to increase the difficulty of building construction in the design of the building, which not only puts higher requirements on the construction technology itself. Different construction techniques are associated in the construction process, which also brings problems to the management of various construction technologies [5]. For example, in construction engineering, steel construction and formwork construction are independent but intertwined. The two are complementary in the actual construction process. If there is a problem in the intersection of the two constructions, it will directly lead to the construction of both. How to strengthen the management of different construction technology departments is also a key issue to be solved in the current construction technology management.

\subsection{The lack of supervision and management of construction engineering technology.}

Within the construction enterprise, there is a clear lack of supervision and management [5]. For example, in the process of carrying out engineering and technical management work, many construction companies did not strictly follow the management norms to carry out various tasks, but the relevant supervisors of the enterprises took an unreasonable attitude and did not follow the operating procedures and the standards of the operating instructions.

\section{Countermeasures for Strengthening Construction Engineering Technology Management}

\subsection{Construction preparation stage.}

Implement the relevant provisions of the Building Law and implement them carefully from the source. Seriously implement all relevant systems, including feasibility studies, review of raw materials, construction technology, security inspection, construction and other operational details [6]. Strictly check every step in the construction process, start from the overall situation, and work together to manage all parts. This requires management technicians not only to grasp the structure of the overall project, but also to value the quality of small projects, and to implement the responsibility for each project.

1) Improve the technical management work standard system. The most basic guarantee for safety and quality of construction engineering is engineering technical standards. It is also a technical specification in the construction field [6]. It must be taken seriously and actively implemented. Training on mandatory standards should be strengthened to improve the ability to master standards and implement standards. Once there is any violation of the mandatory standards, it is resolutely corrected and dealt with, and the responsible person and the unit will be punished in strict accordance with the regulations.

2) Do a good job in the construction drawing review. The key to technical management is to understand the design intent and the quality of key parts of the construction project [7]. After the project has won the bid, we must do a good job in the preparatory work for the construction, especially with the design unit and the supervision unit entrusted by the construction unit to organize the review of the construction drawings.

3) Clear responsibility. It is the person in charge of the construction technology of the construction project that has overall responsibility for the construction quality of the entire project. Its responsibility is to accurately and timely solve various technical problems on the site, that is, to grasp the design intent and understand the purpose of the owner [7]. Foundation, on-site construction is fully carried out in accordance with the design drawings. At the same time, we must also participate in controlling the quality of the incoming materials and semi-finished products.

\subsection{Construction technology control during the construction phase.}

Positions are established in accordance with the technically sound indicator management system, management system and actual needs, and the duties of each management technician are clearly defined. Pay attention to improving the quality of management personnel, implement regular 
vocational training to improve the knowledge theory and professional level of management technicians, organize operators to conduct safety production training, improve safety prevention knowledge, and reduce the chance of accidents [8].

1) Technical disclosure. It is the technical basis for ensuring the construction process and the quality of the project. This is also an important task that can easily be ignored. Throughout the construction process, each sub-item and divisional project must accurately and timely carry out technical disclosure [8]. This is especially true for special and concealed projects, technical requirements for new processes and new structures, basic construction technical requirements, requirements for building materials, and parts that are prone to quality accidents and product protection. This will ensure that the project is completed according to the contract period and quality, and a satisfactory product is provided to the user.

2) Management of project quality. Technical management must fully implement the construction schedule according to the prescribed progress targets [4]. For the actual situation of some work, pay attention to the materials, equipment supply and construction capacity, pay attention to the progress of the unit project image, and adjust the schedule of the follow-up work in time.

3) Management of project progress. The progress management during the construction process is mainly to prepare a certain plan for the project content and procedures during construction, and then put the prepared plan into practice [9]. In the actual construction process, it is necessary to pay attention to whether the construction progress is consistent with the plan. If there is any non-compliance with the plan, it should be adjusted in time and remedial measures should be taken until the project is completed. At the same time, the supervision engineer should cooperate with the management department to take comprehensive measures to control the construction progress.

4) Investment management of the project. To strengthen the construction management of the construction project, it is necessary to strengthen the investment management during the construction process: rationally purchase the mechanical equipment according to the objective requirements of the value law and on the basis of fully investigating the market price [9]. In short, the various cost arrangements during the construction process must be scientific and reasonable. On the basis of formulating correct and reasonable investment in the project, the budget for each stage is correctly prepared.

5) On-site management during construction. On-site management in construction management is to manage and coordinate various elements in the construction site through scientific management methods [9]. These elements mainly include: manpower, mechanical equipment, raw materials, construction environment and Information, etc. Construction site management is to organize the operation of these elements and maintain them in good construction and operation. At the same time, we must also pay attention to the safety of the construction site, because the construction site is almost open-air outdoor operation, there are more manual workers, the construction conditions and environment are more complicated, and the quality of the workers is relatively low, these are all for construction.

\subsection{Construction technology management during the completion phase.}

To carry out reasonable inspection and assessment of the completed project, it is necessary to determine the quality characteristics and characteristics of the completed divisional project, sub-project and unit project by means of certain methods and means, and pass the prescribed quality standards and The results of the measurements are compared to determine if the product is acceptable. All relevant parts and projects that are inconsistent with the prescribed standards shall be reinforced and strengthened after the inspection [6]. All relevant parts and projects that meet the prescribed standards shall be passed after inspection, and those who meet the excellent and good standards shall be given excellent evaluation. According to the stipulated quality standards, it is judged whether it meets the relevant requirements. Fourth, the treatment is to evaluate the finished products of the inspected project, whether it can pass the acceptance, whether it can continue the next step, whether it is necessary to use some methods to remedy [3]. 


\subsection{Establish a professional management team.}

In order to fundamentally improve the construction management level of the construction project, it is necessary to establish a professional management team in the project, so that the management is more professional, so the management team must have a higher management [7]. The professional level can make the management system implement. In the process of construction management, it is necessary to solve the situation of unclear positions and rights and responsibilities in a timely manner.

\subsection{Promote the application of advanced technology and equipment.}

The construction of high-rise buildings is complex and technically difficult. Only advanced process equipment can be used to ensure the construction quality [9]. For example, concrete oscillating tamping, pumping and stirring operations, etc., if it is replaced by manual operation, it is difficult to ensure the quality; using automatic high-polishing and vibration-free method construction, supplemented by manual treatment, can achieve good vibrating effect. Another example is the steel bar engineering, which uses manual treatment and rust removal to ensure quality. The use of advanced mechanical equipment saves manpower, reduces costs, and speeds up progress.

\section{Conclusion}

In 2013, the State Council of the People's Republic of China issued the "Some Opinions on Accelerating the Care of the Aged Service Industry" and set off an "endowment fever" in the land of China. It was called the first year of retirement, and the pension service industry received attention. The cultivation of nursing care professionals is the most important task. It is necessary to constantly explore and innovate in order to meet the needs of this emerging industry and promote the further development of China's pension industry.

\section{References}

[1] X.Y. Qian, Talking about basic construction technology management, Urban Finance, 2007, vol.5, pp.24-26.

[2] X.J. Jiao, To improve the management level of construction engineering technology, Technology to get rich guide, 2014, pp.39-42.

[3] Y.T. Zhang, Discussion on the problems and countermeasures of modern building technology management, Enterprise technology development, 2016, vol.2, pp.153 154.

[4] T.J. Han, The problem that should be paid attention to in the management of construction engineering technology, China high-tech enterprise, 2014, vol.16, pp.104 105.

[5] Sh.Q. Zhao and L.T. Wei, On the issues that should be paid attention to in the construction technology management of building engineering, Enterprise technology development, 2013, vol.3, pp. 178-179.

[6] Sh.H.Gu, Improvement of construction technology management level of construction engineering, Jiangxi building materials, 2017, vol.6, pp.26-27.

[7] X.D. Guo, How to strengthen construction technology management, Technology innovation and application, 2012, vol.23, pp.32-34.

[8] H.F. Zhu, Discussion on optimization measures for construction technology management, Modern property, 2012, vol.3, pp.21-23.

[9] Q.Ch. Yuan and Y.T. Jin, Analysis of measures to strengthen the management of construction engineering technology, Henan Science and Technology, 2013, vol.7, p.52-54. 